\title{
Cross-Cultural Comparisons
}

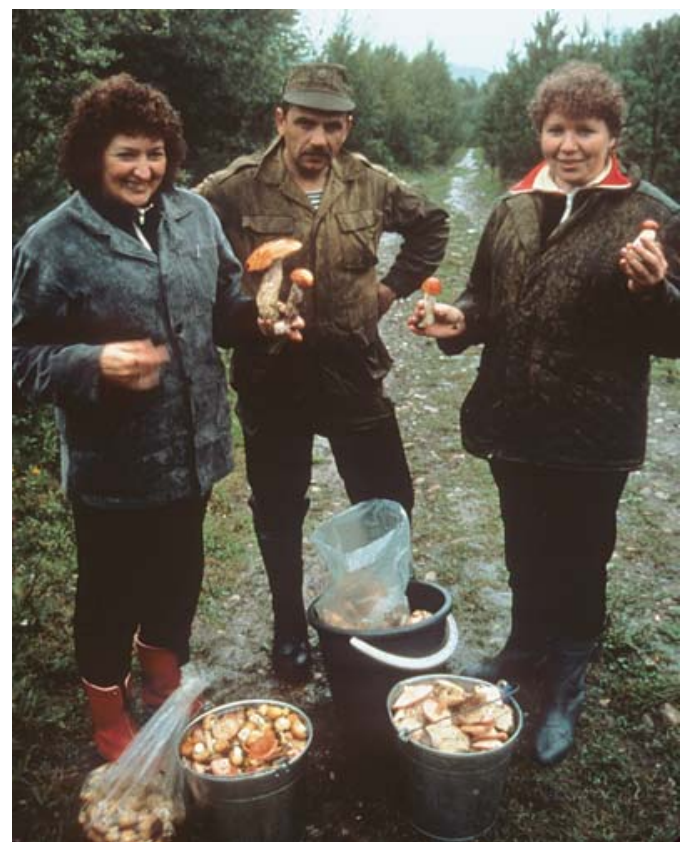

Fig. 1. (David Arora, all rights reserved).

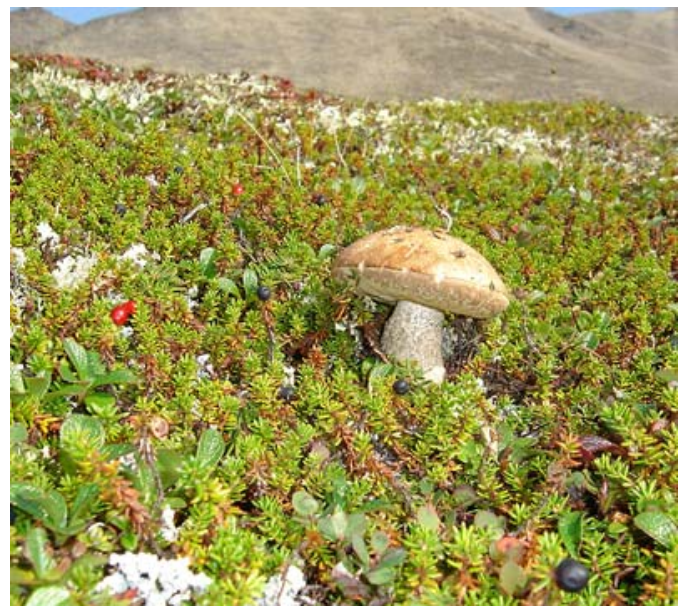

Attitudes toward nature generally, and toward mushrooms more specifically, vary greatly from country to country and from people to people. Russians (Fig. 1) are among the most avid mushroom hunters in the world. When they settled the Chukotka peninsula during the Soviet era, they were delighted to find enormous expanses of tundra "where the mushrooms are taller than the trees" (Fig. 2) (the "trees" being dwarf birches). Yet they were amazed that the indigenous people there barely used them despite an absence of poisonous species. For some Siberian people, such as the Yupiit, mushrooms were a taboo food; for others, such as Chukchi reindeer herders (Fig. 3) wild mushrooms were considered "reindeer food" or "reindeer drugs" and thus unfit for human consumption (see article by Yamin-Pasternak on Beringia).

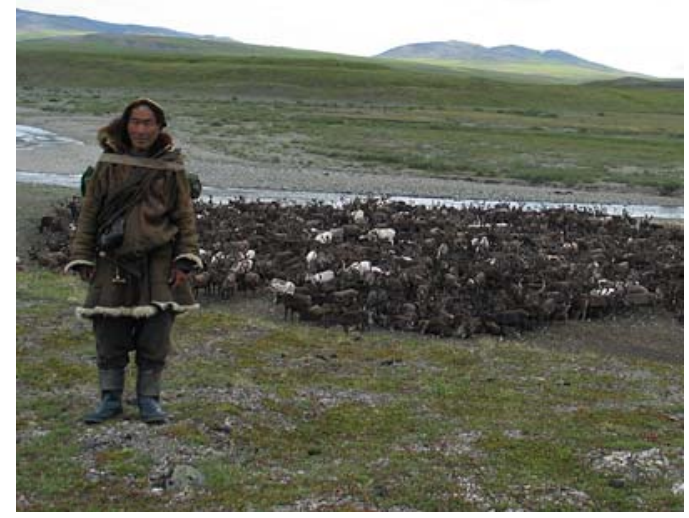

Fig. 3. (Courtesy of the Beringia Park Archives, Provideniya, Chukotka, all rights reserved).

Fig. 2. (Sveta Yamin-Pasternak, all rights reserved).

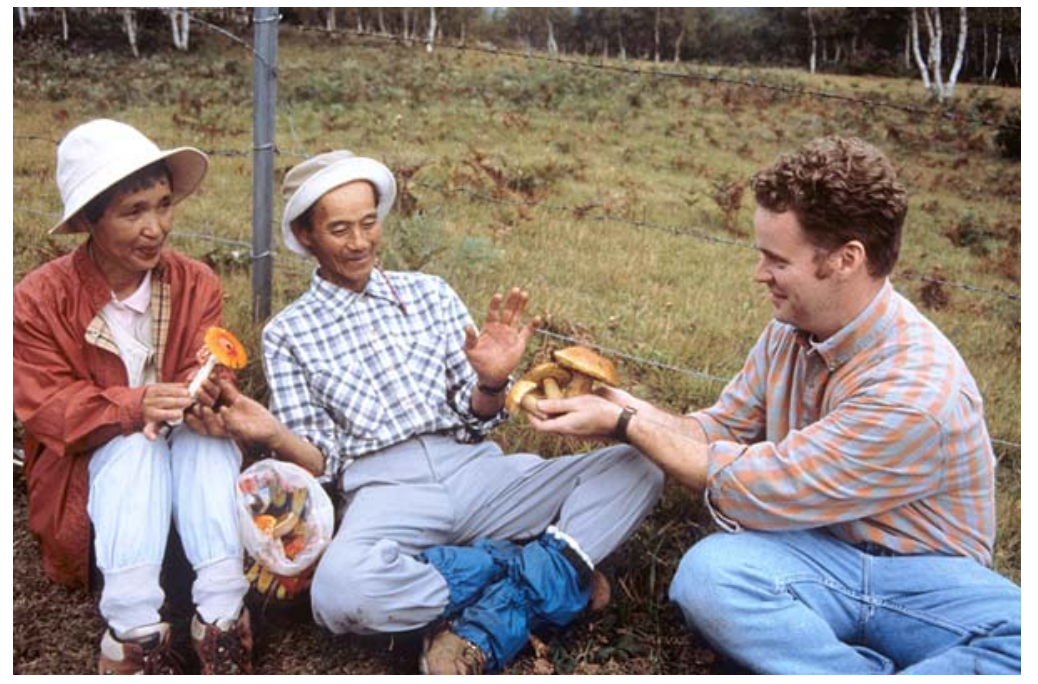

Fig. 4. Porcini are not as esteemed in Asia as they are in Europe and North America. The Chinese are happy to export their porcini (see article by Sitta and Floriani) and keep other, more favored species for themselves. The fly agaric (Amanita muscaria) often grows in the same forests as porcini. In Nagano, Japan, where $A$. muscaria is considered a delicious food, this couple was horrified by researcher Alan Phipps' offer of fresh porcini in exchange for the fly agarics they had gathered (see article by Rubel and Arora on A. muscaria.) (David Arora, all rights reserved). 